James E. Galvin, MD, $\mathrm{MPH}$

David H. Howard, PhD

Sharon S. Denny, MA

Susan Dickinson, MSGC

Nadine Tatton, PhD

Correspondence to

Dr. Galvin:

galvinj@health.fau.edu
Supplemental data at Neurology.org

\title{
The social and economic burden of frontotemporal degeneration OPEN
}

\section{ABSTRACT}

Objective: To quantify the socioeconomic burden of frontotemporal degeneration (FTD) compared to previously published data for Alzheimer disease (AD).

Methods: A 250-item internet survey was administered to primary caregivers of patients with behavioral-variant FTD (bvFTD), primary progressive aphasia, FTD with motor neuron disease, corticobasal syndrome, or progressive supranuclear palsy. The survey included validated scales for disease staging, behavior, activities of daily living, caregiver burden, and health economics, as well as investigator-designed questions to capture patient and caregiver experience with FTD.

Results: The entire survey was completed by 674 of 956 respondents (70.5\%). Direct costs (2016 US dollars) equaled $\$ 47,916$ and indirect costs $\$ 71,737$, for a total annual per-patient cost of $\$ 119,654$, nearly 2 times higher than reported costs for AD. Patients $\geq 65$ years of age, with later stages of disease, and with bvFTD correlated with higher direct costs, while patients $<65$ years of age and men were associated with higher indirect costs. An FTD diagnosis produced a mean decrease in household income from $\$ 75,000$ to $\$ 99,00012$ months before diagnosis to $\$ 50,000$ to $\$ 59,99912$ months after diagnosis, resulting from lost days of work and early departure from the workforce.

Conclusions: The economic burden of FTD is substantial. Counting productivity-related costs, per-patient costs for FTD appear to be greater than per-patient costs reported for AD. There is a need for biomarkers for accurate and timely diagnosis, effective treatments, and services to reduce this socioeconomic burden. Neurology ${ }^{\circledR}$ 2017;89:2049-2056

\section{GLOSSARY}

AD = Alzheimer disease; bvFTD = behavioral-variant frontotemporal degeneration; CPT = Current Procedural Terminology; FTD = frontotemporal degeneration; HRQoL = health-related quality of life; HRS = Health and Retirement Study; HUI3 = Health Utilities Index-3; QALY = quality-adjusted life-years; RUI = Resource Utilization Inventory.

Frontotemporal degeneration (FTD), the most common dementia in individuals $<60$ years of age, affects $\approx 60,000$ individuals in the United States. ${ }^{1-4}$ FTD presents as a diverse group of degenerative disorders with prominent features of language, personality, behavior, cognition, and motor dysfunction made up of 4 predominant clinical phenotypes: behavioral-variant FTD (bvFTD), primary progressive aphasia, FTD with motor neuron disease, and Parkinson-plus movement disorders due to progressive supranuclear palsy or corticobasal syndrome. ${ }^{1,3}$ Although presentations differ, all forms of FTD cause progressive loss of function and independence over 2 to 20 years. ${ }^{1-6}$ The prevalence of FTD is 15 to 22 per 100,000 adults. Compared to Alzheimer disease $(\mathrm{AD}),{ }^{7,8}$ FTD affects younger patients and progresses more rapidly, and patients' symptoms are more variable. Many patients are in their prime earning years, have dependent children, and have difficulty accessing services developed primarily for older adults with dementia. To quantify the socioeconomic burden of FTD, we conducted a web-based survey to characterize

From the Institute for Healthy Aging and Lifespan Studies (J.E.G.), Charles E. Schmidt College of Medicine, Florida Atlantic University, Boca Raton; Emory University (D.H.H.), Atlanta, GA; and Association for Frontotemporal Degeneration (S.S.D., S.D., N.T.), Radnor, PA

Go to Neurology.org for full disclosures. Funding information and disclosures deemed relevant by the authors, if any, are provided at the end of the article. The Article Processing Charge was funded by the Association for Frontotemporal Degeneration.

This is an open access article distributed under the terms of the Creative Commons Attribution-NonCommercial-NoDerivatives License 4.0 (CC BY-NC-ND), which permits downloading and sharing the work provided it is properly cited. The work cannot be changed in any way or used commercially without permission from the journal. 
the patient and caregiver experience with FTD-related resource use, health-related quality of life (HRQoL), and per-patient annual costs.

METHODS Standard protocol approvals, registrations, and patient consents. The Florida Atlantic University Institutional Review Board approved the study as exempt.

Survey design. Participants $(n=956)$ were recruited via announcements on the Association for Frontotemporal Degeneration website, newsletter, social media, and e-mail blasts. We designed a 250-question internet survey using Qualtrics Survey Software (Provo, UT) to characterize the socioeconomic burden of FTD from the primary caregivers' perspective. No identifiable personal information was collected. Validated scales for clinical characterization and resource use were used whenever available and are described below. We used investigator-generated questions to describe the personal burden of FTD when no validated scale existed. We used these data to estimate the economic burden of FTD. The survey was beta-tested and revised for clarity and readability before its release to the FTD community. The survey took $\approx 2$ hours to complete.

Clinical characterization. Informant-based questionnaires characterized the patient's symptoms and severity. The 10question Quick Dementia Rating Scale ${ }^{9}$ staged dementia severity (range $0-30$, higher scores reflect greater impairment). The 12-question Neuropsychiatric Inventory ${ }^{10}$ assessed behavioral aspects of disease (range 0-36, higher scores indicate more behavioral symptoms). The 10-question Functional Activities Questionnaire ${ }^{11}$ examined instrumental activities of daily living (range 0-30, higher scores mean greater functional dependence). The 12-question Zarit Burden Inventory ${ }^{12}$ assessed caregivers' burden (range $0-36$, higher scores mean greater burden). In addition, respondents assessed patient disease stage severity at the time of the survey on the basis of their opinion and direct observation of the patient ${ }^{13,14}$ as mild, moderate, severe, or terminal (capturing the last 6 months of life).

Health utility and resource use. We measured patients' quality of life and health utility using the Health Utilities Index-3 (HUI3). ${ }^{15,16}$ The HUI3 measures health-state utility and provides a summary score for HRQoL across 8 attributes (vision, hearing, speech, ambulation, dexterity, emotion, cognition, pain), with each attribute having 5 or 6 levels of ability/disability for a total 972,000 unique health states. The HUI3 provides utility scores ranging from 1 (reflecting perfect health) to 0 (dead) with negative scores possible (minimum score -0.371 ) and reflecting health states deemed "worse than being dead." ${ }^{15}$ We estimated quality-adjusted life-years (QALYs), representing quality-adjusted life expectancy, by multiplying health utility by survival time. ${ }^{17}$ As is the case with health utility, negative QALYs are possible, reflecting survival in health states being worse than death. Negative HUI3 and QALY scores reflect the respondents' belief that there is no perceived positive quality of life for the patient in this state.

The Resource Utilization Inventory (RUI) ${ }^{18,19}$ measures patient and caregiver dementia-associated costs, the use of formal and informal care, and the loss of paid employment. There are 4 domains: direct medical care, direct nonmedical care, informal care, and caregiver time. Actual costs are determined via Current Procedural Terminology (CPT) codes, Evaluation and Management codes, and Diagnosis Related Groups. We calculated the mean response for each resource use question. We omitted missing values unless the patient resided in dependent care and the resource is used primarily by community-dwelling patients (i.e., home health aides). In that case, we assumed that the respondent did not use that resource in the event of nonresponse. There were no differences between completers and noncompleters for any variable after correction for multiple comparisons.

We assigned dollar values to hospital admissions on the basis of the admission-weighted average of Medicare reimbursements for Diagnosis Related Groups 56 and 57 (degenerative nervous system disorders, with and without a major complication or comorbidity). We used the Medicare reimbursement for an Evaluation and Management visit for an established patient (CPT 99214) to assign a dollar value to office visits and CPT 97110 to assign a dollar value to physical therapy visits. We used estimates from Genworth ${ }^{20}$ to assign dollar values to assisted living care, nursing home care, and respite care. We adjusted nursing home and assisted living costs downward by $8 \%$ to account for the costs of food and shelter. ${ }^{21}$ We obtained costs for medical equipment from the Medicare fee schedule. ${ }^{22}$

We estimated costs for paid home care using Genworth ${ }^{20}$ and costs for unpaid care using wage estimates from the Bureau of Labor Statistics. ${ }^{23,24}$ Table e-1 at Neurology.org provides details for cost estimates. We estimated lost productivity by asking whether patients and caregivers were out of the labor force as a result of FTD. We valued lost productivity for patients using average annual earnings ${ }^{25}$ multiplied by 1.25 to account for fringe benefits. We valued lost productivity for caregivers by subtracting the annual cost of hiring a home health aide from average earnings.

We calculated the annual per patient costs considering direct costs (patient medical care, patient residential care, respite care, patient medical equipment and supplies, and paid home care with formal caregivers) and indirect costs (unpaid home care for family and friends, patient lost wages, and caregiver lost wages). Average costs were determined by multiplying the average use by the price per item. For example, patients experienced an average of 0.6 hospitalizations per year. If the typical reimbursement per admission is $\$ 36,044$, then the average cost in the sample is $\$ 21,626(0.6 \times$ $\$ 36,044)$. We calculated direct and indirect costs by summing across average costs for individual RUI items. Some respondents answered only a subset of the cost-related questions. We calculated average costs on the basis of the subsample of respondents who answered the relevant questions for each cost item.

Statistical analyses. Analyses were conducted with SPSS version 23 (IBM Corp, Armonk, NY). Descriptive statistics characterized the caregiver respondents and the patients. We compared groups using analysis of variance for continuous variables and $\chi^{2}$ tests for categorical variables. We compared median incomes using Kruskal-Wallis tests. We used a generalized linear model with a gamma distribution and log link to estimate the relationship between patient-level costs and patient characteristics and summed costs by item at the individual level. We restricted the sample to respondents who had nonmissing responses for at least 15 of the 18 RUI items ( $\mathrm{n}=595$ respondents) and recoded any remaining missing values to zero. We selected the cutoff of 15 to balance the benefit of including as many respondents in the analysis as possible against the disadvantage of including respondents with incomplete cost data. Respondents who answered 15 items were similar in terms of sex, age, disease type, and disease duration to respondents who answered $<15$.

RESULTS Sample characteristics. Nine hundred fiftysix individuals started the survey, and 674 (70.5\%) completed it. There were no significant demographic 
differences between completers and noncompleters. The patients were divided into 4 groups (table 1) based on the caregiver's assessment: mild, moderate, severe, or terminal. The majority of caregiver respondents were female spouses, while the majority of patients were men. The diagnostic groups were $52.9 \%$ bvFTD, $21.1 \%$ primary progressive aphasia, 7.3\% FTD with motor neuron disease, and 5.4\% progressive supranuclear palsy or corticobasal syndrome, while $13.3 \%$ were undefined FTD (i.e., the respondent did not know the subtype). As demonstrated in table 1 , the caregiver global ratings matched well with duration of disease and standardized rating scales of global staging (Quick Dementia Rating Scale), ${ }^{9}$ behavior (Neuropsychiatric Inventory), ${ }^{10}$ and function (Functional Activities Questionnaire). ${ }^{11}$ Caregiver burden (Zarit Burden Inventory) ${ }^{12}$ was not different across stages of disease.

Changes in household income and lost days of work. At the time of survey, $45 \%$ of caregivers still worked, while $37 \%$ were no longer employed after the patient's FTD diagnosis. Seventy-four percent of caregivers worked full-time. Only 3.3\% of patients were still working. Caregivers reported lost days of work due to patient health issues $(25.6 \%)$ or caregiver health issues $(21.6 \%)$. Caregivers and patients who were still working full-time reported a median loss of 7.0 days over the previous 4 weeks due to FTDrelated matters.

Respondents provided the total household income for the patient and family 12 months before and 12 months after the FTD diagnosis (table 2). The overall household income before diagnosis ranged from $\$ 75,000$ to $\$ 99,000$ but declined after diagnosis to $\$ 50,000$ to $\$ 59,999(p<0.001)$. There were no differences in the extent of loss of household income by FTD subtype, caregiver type, or patient sex (table 2).

Patient and caregiver health costs associated with FTD. We found that $67 \%$ of caregivers of patients with FTD reported a notable decline in their health and that $53 \%$ reported increased personal health care costs calculated from the RUI. On average, caregivers had 7 clinician visits and slightly less than 1 inpatient admission per year. On average, patients had 6 overnight respite stays, 16 daytime respite stays, 35 clinician visits, and 2 hospital or emergency room visits. In addition, $31.6 \%$ of respondents needed to hire a paid caregiver several times per week.

Estimates of annual per patient costs. Total direct costs (i.e., the value of goods and services for which there are explicit monetary payments) were $\$ 47,916$. Total

\begin{tabular}{|c|c|c|c|c|c|}
\hline Sample characteristics & & & & & \multirow[b]{3}{*}{$p$ Value } \\
\hline \multirow[b]{2}{*}{ Variable } & \multicolumn{4}{|c|}{ Stage of FTD } & \\
\hline & Mild & Moderate & Severe & Terminal & \\
\hline CG age, y & $58.7(9.2)$ & $60.9(9.8)$ & $61.5(10.0)$ & $61.0(11.1)$ & 0.28 \\
\hline CG, \% female & 88.9 & 82.4 & 73.2 & 74.2 & 0.006 \\
\hline CG relationship, \% & & & & & 0.03 \\
\hline Spouse & 79.6 & 84.1 & 80.0 & 74.2 & \\
\hline Child & 9.3 & 8.0 & 13.1 & 17.7 & \\
\hline Patient age, y & $64.5(10.5)$ & $65.6(8.1)$ & $66.2(8.8)$ & $67.9(8.1)$ & 0.14 \\
\hline Patients, \% female & 22.6 & 27.0 & 37.3 & 40.3 & 0.007 \\
\hline FTD diagnosis, \% & & & & & 0.32 \\
\hline bvFTD & 63.0 & 55.7 & 47.9 & 54.1 & \\
\hline Progressive aphasia & 13.0 & 19.1 & 24.9 & 21.3 & \\
\hline MND spectrum & 7.4 & 7.7 & 7.3 & 4.9 & \\
\hline PSP or CBS & 7.5 & 4.1 & 5.8 & 6.6 & \\
\hline Other or nonspecified & 9.3 & 13.4 & 14.1 & 13.1 & \\
\hline Duration of disease, $y$ & $2.4(2.1)$ & 3.8 (3.1) & $5.7(3.4)$ & $6.3(4.1)$ & $<0.001$ \\
\hline Quick Dementia Rating System & $6.9(3.1)$ & $14.5(5.3)$ & $23.9(5.3)$ & $25.5(4.5)$ & $<0.001$ \\
\hline Functional Activities Questionnaire & $10.6(6.7)$ & 20.4 (7.3) & $26.9(5.5)$ & $27.2(5.5)$ & $<0.001$ \\
\hline Neuropsychiatric Inventory & $7.9(4.9)$ & $12.3(6.3)$ & $13.5(7.2)$ & $16.6(9.8)$ & $<0.001$ \\
\hline Zarit Burden Inventory & $25.4(10.9)$ & $27.7(7.6)$ & 28.3 (7.9) & 28.1 (7.6) & 0.16 \\
\hline
\end{tabular}

Abbreviations: bvFTD = behavioral variant of frontotemporal degeneration; $\mathrm{CBS}=$ corticobasal syndrome; $\mathrm{CG}=$ caregiver; $\mathrm{FTD}=$ frontotemporal degeneration; MND = motor neuron disease; PSP = progressive supranuclear palsy.

Values are mean (SD). 
Table 2 Change in median household income

\begin{tabular}{|c|c|c|c|c|c|}
\hline & Total & \multicolumn{4}{|l|}{ FTD subtype } \\
\hline 12 mo before DX, \$ & $75,000-99,999$ & $75,000-99,999$ & $75,000-99,999$ & $60,000-74,999$ & $50,000-59,999$ \\
\hline 12 mo after DX, s & $50,000-59,999$ & $50,000-59,999$ & $50,000-59,999$ & $35,000-49,999$ & $40,000-49,999$ \\
\hline \multirow[t]{3}{*}{$p$ Value } & $<0.001$ & $<0.001$ & $<0.001$ & 0.001 & 0.003 \\
\hline & \multicolumn{3}{|l|}{ Type of caregiver } & \multicolumn{2}{|l|}{ Patient sex } \\
\hline & Spouse CG & Child CG & Other CG & Male & Female \\
\hline 12 mo before $\mathrm{DX}, \$$ & $75,000-99,999$ & $40,000-49,999$ & $75,000-99,999$ & $75,000-99,999$ & $75,000-99,999$ \\
\hline 12 mo after DX, \$ & $50,000-59,999$ & $30,000-34,999$ & $35,000-39,999$ & $50,000-59,999$ & $40,000-49,999$ \\
\hline$p$ Value & $<0.001$ & 0.001 & $<0.001$ & $<0.001$ & $<0.001$ \\
\hline
\end{tabular}

Abbreviations: bvFTD = behavioral variant of frontotemporal degeneration; CG = caregiver; DX = diagnosis; FTD-MND = frontotemporal degeneration with motor neuron disease; PPA = primary progressive aphasia; PSP/CBS = progressive supranuclear palsy/corticobasal syndrome.

Median ranges.

indirect costs (the value of the changes in the provision of goods and services that are attributable to FTD but for which there are no explicit monetary payments) were $\$ 71,737$. The sum of estimated direct and indirect costs is $\$ 119,654$.

Table 3 reports the relationship between patient characteristics and costs. The sample used in the regression analysis had a higher proportion of men $(69 \%$ vs $61 \%$ ) but was otherwise similar in terms of age, stage, underlying diagnosis, and disease duration. Patients $\geq 65$ years of age incurred higher direct costs $(\$ 17,900)$ but lower indirect costs $(\$ 25,000)$. Men had higher indirect costs because they were more likely to use unpaid care and to have stopped working because of the disease. Women had higher direct costs, mainly because they were more likely to live in nursing homes or assisted living facilities. Patients with severe or terminal stages of disease incurred higher direct costs $(\$ 54,000)$. Across the FTD subtypes, bvFTD had higher direct costs $(\$ 13,030)$ than other subtypes.

Other costs associated with FTD. Caregivers also reported patient-related crises during the prior year: $19 \%$ required an emergency department visit, $11 \%$ required emergency medical services, $8 \%$ required urgent psychiatric care, $6 \%$ required police intervention, and $6 \%$ required contacting a lawyer. Poor financial decisions by patients with FTD were reported by $58 \%$ of respondents. Legal costs were reported by $9.6 \%$ of respondents, attributed largely to court appearances and attorney fees. The leading reasons for court appearances included legal guardianship (9.0\%), bankruptcy (4.4\%), loss of home $(3.9 \%)$, loss of business $(3.8 \%)$, criminal cases (3.2\%), and civil lawsuits (2.7\%). The leading reasons for attorney fees included initiating a power of attorney (25.9\%), revising wills (22.9\%), guardianships $(7.6 \%)$, and court appearances $(5.8 \%)$.

Changes in HRQoL. Table 4 reports HUI3 ${ }^{15,16}$ scores and QALYs ${ }^{17}$ by severity of disease, FTD subtype, and caregiver-patient dyadic relationships. HUI3 scores and QALYs were lower for patients in the severe and terminal stages, with scores indicating that patients' quality of life is worse than dead $(p<$ 0.001). Across all stages of disease, caregivers reported declines in HRQoL regardless of relationship; however, QALYs were highest in female caregiver-male

Table 3 Estimates from generalized linear models

\begin{tabular}{|c|c|c|c|c|c|c|c|}
\hline \multirow[b]{2}{*}{ Variable } & \multirow[b]{2}{*}{ n (\%) } & \multicolumn{6}{|l|}{ Effects, $\$ 1,000(95 \% \mathrm{Cl})$} \\
\hline & & Direct costs & $p$ Value & Indirect costs & $p$ Value & Total costs & p Value \\
\hline Male & $415(69.7)$ & $-6.89(-17.33$ to 3.55$)$ & 0.19 & 17.18 (8.69 to 25.67 ) & $<0.001$ & 13.03 (2.68 to 23.38 ) & 0.01 \\
\hline Severe stage & 281 (47.2) & $54.43(40.83,68.03)$ & $<0.001$ & $-3.18(-11.03$ to 4.67$)$ & 0.43 & 46.38 (36.14 to 56.62 ) & $<0.001$ \\
\hline Duration 2-6 y & 346 (58.2) & $-2.06(-12.30$ to 8.18$)$ & 0.69 & 9.29 (1.34 to 17.24$)$ & 0.02 & $5.99(-3.92$ to 15.90$)$ & 0.24 \\
\hline Duration $>6 y$ & $141(23.7)$ & $1.57(-10.43$ to 13.57$)$ & 0.79 & 5.95 (-3.58 to 15.48$)$ & 0.22 & $3.37(-8.43$ to 15.17$)$ & 0.58 \\
\hline
\end{tabular}

Abbreviations: bvFTD = behavioral variant of frontotemporal degeneration; $\mathrm{Cl}=$ confidence interval Estimates (95\% Cls). 
Table 4 Health-related quality of life

\begin{tabular}{|c|c|c|c|c|c|}
\hline Variable & \multicolumn{4}{|c|}{ Stage of FTD } & p Value \\
\hline НUІз & $0.55(0.27)$ & $0.24(0.27)$ & $-0.09(0.20)$ & $-0.17(0.15)$ & $<0.001$ \\
\hline \multirow[t]{2}{*}{ QALYs } & $1.2(1.5)$ & $0.8(1.5)$ & $-0.64(1.4)$ & $-1.03(0.9)$ & $<0.001$ \\
\hline & \multicolumn{4}{|c|}{ Caregiver-patient dyads } & \\
\hline НUІз & $0.09(0.29)$ & $0.09(0.32)$ & $0.13(0.32)$ & $0.02(0.28)$ & 0.08 \\
\hline \multirow[t]{2}{*}{ QALYs } & $0.21(0.9)$ & $0.25(1.9)$ & $0.27(1.6)$ & $-0.50(1.2)$ & 0.006 \\
\hline & \multicolumn{4}{|l|}{ FTD subtype } & \\
\hline Variable & bvFTD & PPA & FTD-MND & PSP/CBS & $p$ Value \\
\hline
\end{tabular}

Abbreviations: bvFTD = behavioral variant of frontotemporal degeneration; FTD = frontotemporal degeneration; FTD-MND = frontotemporal degeneration with motor neuron disease; HUI3 = Health Utilities Index-3; PPA = primary progressive aphasia; PSP/CBS = progressive supranuclear palsy and corticobasal syndrome; QALY = quality-adjusted life-year.

Values are mean (SD).

patient dyads and lowest in female caregiver-female patient dyads. There were no significant differences in HRQoL or QALYs by FTD subtypes.

Comparison to economic costs of AD. Lastly, we examined the cost analyses for annual direct, indirect, and total costs reported for patients with dementia in previous studies (table 5). Most of the cited studies examined patients with $\mathrm{AD}$, mild cognitive impairment due to $\mathrm{AD}$, or nonspecified dementia. These studies used a variety of data collection strategies, including record reviews, structured interviews, and validated scales. Studies from non-US sources were converted to 2016 US dollars for comparison. Reported costs were higher in more advanced stages of dementia $^{26}$ and in younger-onset and non-AD dementias. ${ }^{19,27}$ Costs were greater in the United States than in studies originating in other countries. Most studies did not account for lost wages in the calculation of indirect costs and used HRQoL or QALYs to assess influence on quality of life. Across studies, inability to complete activities of daily living, worsening behavior, caregiver burden, the number of comorbid medical conditions, and increasing severity of disease were associated with higher costs.

One of the largest studies in the United States examining dementia $\operatorname{costs}^{21}$ used a subsample of 856 patients from the Health and Retirement Study (HRS). This study reported a number of different cost estimates, which varied based on how unpaid care was valued and whether costs were adjusted for coexisting conditions, to report annual direct costs of $\$ 33,329$ and annual indirect costs of $\$ 30,839$ (total annual costs: $\$ 64,168)$. Their estimate of costs unadjusted for coexisting conditions with unpaid care valued at the replacement cost (i.e., the cost of hiring a paid home health worker) is comparable to our findings. However, overall costs of dementia care estimated from the HRS data were 53\% lower than our reported total costs for FTD, or a total of $\$ 119,653$.

DISCUSSION FTD is associated with substantial direct and indirect costs, diminished quality of life, and increased caregiver burden. Most patients with FTD are working age, and most patients have to leave the labor force during their peak earning years. Caregivers of patients with FTD may also need to alter their careers to provide care. Combined, these factors contribute to a substantial decrease in household income. Previous studies have documented the heavy burden imposed by FTD on caregivers and families, ${ }^{28,29}$ but there has not been a study to date that captured the economic burden of FTD in the US.

A clinic-based study from Singapore ${ }^{27}$ that examined differences in median annual costs between young- and late-onset dementia reported youngonset dementia costs almost twice those of lateonset dementia in the clinic patient group $(\$ 15,815$ vs $\$ 8,396)$. This same study found that FTD and vascular dementia had higher costs than youngonset AD. Another study in Argentina ${ }^{30}$ found annual direct costs for FTD to be higher than for $\mathrm{AD}$, with at least part of that cost accounted for by psychotropic medications. Most studies have reported that resource use (institutional care, community care, home services) was highly correlated with dependency for activities of daily living and behavior. This is 
Table 5 Comparison of direct, indirect, and total costs associated with dementia care

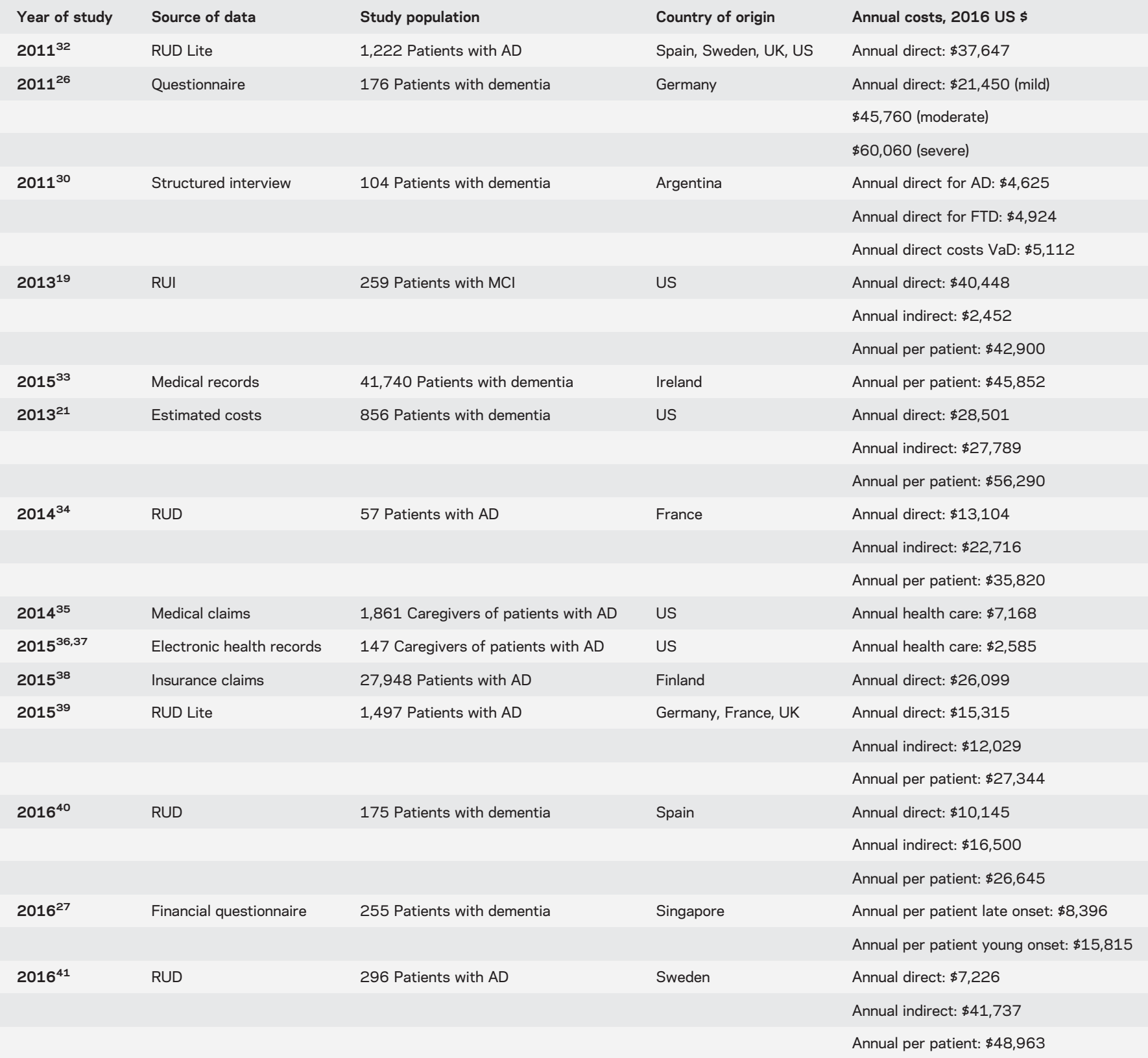

Abbreviations: $\mathrm{AD}=$ Alzheimer disease; $\mathrm{FTD}=$ frontotemporal degeneration; $\mathrm{MCl}=$ mild cognitive impairment; RUD = Resource Utilization in Dementia; $\mathrm{RUI}=$ Resource Utilization Inventory; $\mathrm{VaD}=$ vascular dementia.

consistent with our finding that direct costs were significantly higher in bvFTD compared with other FTD subtypes.

Our study found that the economic burden for FTD in the United States is approximately twice that reported for $\mathrm{AD} .{ }^{21}$ Given the age of the population affected by $\mathrm{AD}$, the authors did not estimate productivity-related costs. When productivityrelated costs are excluded and just direct costs and informal care costs are considered, our estimate of $\$ 69,000$ per patient cost for FTD is similar to their estimate of the $\$ 64,000$ per patient cost of $\mathrm{AD}$ dementia in the United States. However, because many patients with FTD and their caregivers would otherwise be in the labor force, the true per-patient economic burden of FTD may be substantially higher than for $\mathrm{AD}$. It is worth noting that the reported $\mathrm{AD}$ per-patient care costs vary widely (table 5) and may reflect the impact that different methodologies have on generating cost estimates.

Our study has limitations. Individuals with an inherently positive view of research were more likely to respond to an invitation to participate. Not all individuals who initiated the survey completed the survey, but we found no sociodemographic differences between completers and noncompleters. We relied 
on self-reported resource use data, which may be subject to inaccurate recall. To counter this, we used wellaccepted, validated instruments in dementia research (e.g., RUI and HUI3). Our sample population was caregivers rather than the patients themselves, and all diagnoses are self-reported. To overcome this, we used well-validated informant rating scales to assess presence and stage of dementia, activities of daily living, behavior, and HRQoL to characterize the patients. It is worth noting that in a disease with no formal clinical staging, caregivers' assessment of stage of disease strongly correlated across all validated staging, functional, and behavioral instruments. Finally, this study was cross-sectional and is unable to estimate longitudinal costs associated with disease progression.

Our finding of an increased economic burden for FTD compared to what is reported for AD may still underestimate true costs. Our cost estimates were based on items for which we could assign a unit cost to the item without making speculative assumptions and reasonably attribute the cost to FTD vs other illnesses. Therefore, while we measured caregiver's use of medical services, we did not assign a monetary value and could not determine what share of care is attributable to the unique burden of FTD caregiving without undertaking additional analyses. ${ }^{29}$

Although the absolute number of patients with FTD is lower than the number with $\mathrm{AD}$, the economic burden of FTD is substantial. One of the key factors to this burden may be the earlier age at onset, typically occurring during patients' or caregivers' peak earning years. A better understanding of the substantial socioeconomic burden of FTD will provide the needed evidence base to help inform healthcare policy, ${ }^{31}$ to drive research agendas, and to enhance targeted allocation of resources that will lead to timely and accurate diagnosis and effective treatments where none now exists.

\section{AUTHOR CONTRIBUTIONS}

Dr Galvin: study and questionnaire design, statistical analyses and interpretation, drafting, revising, and submitting the manuscript. Dr Howard: questionnaire design, statistical analyses, reviewing and editing the manuscript. Ms. Denny, Ms. Dickinson, and Dr Tatton: questionnaire design, reviewing and editing the manuscript.

\section{ACKNOWLEDGMENT}

The authors thank the many families who responded to the survey.

\section{STUDY FUNDING}

This study was supported by a grant from the Association for Frontotemporal Degeneration (Radnor, PA).

\section{DISCLOSURE}

J. Galvin serves as a scientific advisor for Axovant, Biogen, Eisai, and Eli Lilly; receives licensing fees from Pfizer, Lilly, Axovant, and Quintiles; and is funded by grants from the NIH (R01 AG0402-11-A1, U01 NS100610, and R01 NS088040-01), the Florida Department of Health, the Mangurian Foundation, and the Association for Frontotempora
Degeneration. He is on the editorial boards of Neurodegenerative Disease Management, Alzheimer's Disease and Associated Disorders, and Acta Neuropathologica. D. Howard has served as a consultant for the Association for Frontotemporal Degeneration and the Center for Discovery. S. Denny, S. Dickinson, and N. Tatton are employees of the Association for Frontotemporal Degeneration. Go to Neurology.org for full disclosures.

Received March 1, 2017. Accepted in final form August 25, 2017.

\section{REFERENCES}

1. Perry DC, Miller BL. Frontotemporal dementia. Semin Neurol 2013;33:336-341.

2. Ratnavalli E, Brayne C, Dawson K, Hodges JR. The prevalence of frontotemporal dementia. Neurology 2002;58: $1615-1621$.

3. Snowden JS, Neary D, Mann DM. Frontotemporal dementia. Br J Psychiatry 2002;180:140-143.

4. Knopman DS, Roberts RO. Estimating the number of persons with frontotemporal lobar degeneration in the US population. J Mol Neurosci 2011;45:330-335.

5. Diehl J, Kurz A. Frontotemporal dementia: patient characteristics, cognition, and behaviour. Int J Geriatr Psychiatry 2002;17:914-918.

6. Jicha GA, Nelson PT. Management of frontotemporal dementia: targeting symptom management in such a heterogeneous disease requires a wide range of therapeutic options. Neurodegener Dis Manag 2011;1:141-156.

7. Mayeux R, Stern Y. Epidemiology of Alzheimer disease. Cold Spring Harb Perspect Med 2012;2:a006239.

8. Onyike CU, Diehl-Schmid J. The epidemiology of frontotemporal dementia. Int Rev Psychiatry 2013;25: 130-137.

9. Galvin JE. The Quick Dementia Rating System (QDRS): a rapid dementia staging tool. Alzheimer Dement 2015;1: 249-259.

10. Kaufer DI, Cummings JL, Ketchel P, et al. Validation of the NPI-Q, a brief clinical form of the Neuropsychiatric Inventory. J Neuropsychiatry Clin Neurosci 2000;12: 233-239.

11. Pfeffer RI, Kurosaki TT, Harrah CH Jr, Chance JM, Filos S. Measurement of functional activities in older adults in the community. J Gerontol 1982;37:323-329.

12. Herbert R, Bravo G, Preville M. Reliability, validity, and reference values of the Zarit Burden Interview for assessing informal caregivers of community-dwelling older persons with dementia. Can J Aging 2000;19: 494-507.

13. Galvin JE, Duda JE, Kaufer DI, Lippa CF, Taylor A, Zarit SH. Lewy body dementia: caregiver burden and unmet needs. Alzheimer Dis Assoc Disord 2010;24: 177-181.

14. Galvin JE, Duda JE, Kaufer DI, Lippa CF, Taylor A, Zarit $\mathrm{SH}$. Lewy body dementia: the caregiver experience of clinical care. Parkinsonism Relat Disord 2010;16:388-392.

15. Neumann PJ, Sandberg EA, Araki SS, Kuntz KM, Feeny D, Weinstein MC. A comparison of HUI2 and HUI3 utility scores in Alzheimer's disease. Med Decis Making 2000;20: 413-422.

16. Kavirajan H, Hays RD, Vassar S, Vickrey BG. Responsiveness and construct validity of the Health Utilities Index in patients with dementia. Med Care 2009;47:651-661.

17. Tong T, Thokala P, McMillan B, Ghosh R, Brazier J. Cost effectiveness of using cognitive screening tests for detecting dementia and mild cognitive impairment in primary care. Int J Geriatr Psychiatry Epub 2016 Nov 22. 
18. Sano M, Zhu C, Whitehouse PJ, et al. ACDS Prevention Instrument Project: pharmacoeconomics: assessing health related resource use among healthy elderly. Alzheimer Dis Assoc Disord 2006;20:S191-S202.

19. Zhu CW, Sano M, Ferris SH, Whitehouse PJ, Patterson MB, Aisen PS. Health-related resource use and costs in elderly adults with and without mild cognitive impairment. J Am Geriatr Soc 2013;61:396-402.

20. Genworth Cost of Care Survey [online]. Available at: https://www.genworth.com/about-us/industry-expertise/ cost-of-care.html. Accessed December 22, 2016.

21. Hurd MD, Martorell P, Delavande A, Mullen KJ, Langa KM. Monetary costs of dementia in the United States. N Engl J Med 2013;368:1326-1334.

22. Center for Medicare \& Medicaid Services. DMEPOS fee schedule. Available at: https://www.cms.gov/Medicare/ Medicare-Fee-for-Service-Payment/DMEPOSFeeSched/ DMEPOS-Fee-Schedule.html. Accessed January 12, 2017.

23. Bureau of Labor Statistics. Home health aides. In: Occupational Outlook Handbook [online]. Available at: https:// www.bls.gov.ooh/healthcare/home-health-aides.htm. Accessed December 22, 2016.

24. Bureau of Labor Statistics. May 2015 national occupational employment and wage estimates United States: healthcare practitioners and technical occupations [online]. Available at: https://www.bls.gov/oes/current/oes_nat. htm\#29-0000. Accessed February 6, 2017.

25. Bureau of Labor Statistics. May 2015 national occupational employment and wage estimates United States: all occupations [online]. Available at: https://www.bls.gov/ oes/current/oes_nat.htm\#00-0000. Accessed December 22, 2016.

26. Leicht H, Heinrich S, Heider D, et al; AgeCoDe Study Group. Net costs of dementia by disease stage. Acta Psychiatr Scand 2011;124:384-395.

27. Kandiah N, Wang V, Lin X, et al. Cost related to dementia in the young and the impact of etiological subtype on cost. J Alzheimers Dis 2016;49:277-285.

28. Caceres BA, Frank MO, Jun J, Martelly MT, Sadarangani T, Sales PC. Family caregivers of patients with frontotemporal dementia: an integrative review. Int J Nur Stud 2016;55: 71-84.

29. Diehl-Schmid J, Schmidt EM, Nunnemann S, et al. Caregiver burden and needs in frontotemporal dementia. J Geriatr Psychiatry Neurol 2013;26:221-229.
30. Rojas G, Bartoloni L, Dillon C, Serrano CM, Iturry M, Allegri RF. Clinical and economic characteristics associated with direct costs of Alzheimer's, frontotemporal and vascular dementia in Argentina. Int Psychogeriatr 2011;23: 554-561.

31. Prince MJ, Wu F, Guo Y, et al. The burden of disease in older people and implications for health policy and practice. Lancet 2015;385:549-562.

32. Gustavsson A, Brinck P, Bergvall N, et al. Predictors of costs of care in Alzheimer's disease: a multinational sample of 1222 patients. Alzheimers Dement 2011;7:318-327.

33. Connolly S, O'Shea E. The impact of dementia on length of stay in acute hospitals in Ireland. Dementia 2015;14: 650-658.

34. Gervès C, Chauvin P, Bellanger MM. Evaluation of full costs of care for patients with Alzheimer's disease in France: the predominant role of informal care. Health Policy 2014;116:114-122.

35. Suehs BT, Shah SN, Davis CD, et al. Household members of persons with Alzheimer's disease: health conditions, healthcare resource use, and healthcare costs. J Am Geriatr Soc 2014;62:435-441.

36. Zhu CW, Scarmeas N, Ornstein K, et al. Health-care use and cost in dementia caregivers: longitudinal results from the Predictors Caregiver Study. Alzheimers Dement 2015; 11:444-454.

37. Zhu CW, Cosentino S, Ornstein K, et al. Medicare utilization and expenditures around incident dementia in a multiethnic cohort. J Gerontol A Biol Sci Med Sci 2015;70:1448-1453.

38. Tolppanen AM, Taipale H, Purmonen T, Koponen M, Soininen H, Hartikainen S. Hospital admissions, outpatient visits and healthcare costs of community-dwellers with Alzheimer's disease. Alzheimers Dement 2015;11: 955-963.

39. Dodel R, Belger M, Reed C, et al. Determinants of societal costs in Alzheimer's disease: GERAS study baseline results. Alzheimers Dement 2015;11:933-945.

40. Farré M, Haro JM, Kostov B, et al. Direct and indirect costs and resource use in dementia care: a cross-sectional study in patients living at home. Int J Nurs Stud 2016;55: $39-49$.

41. Åkerborg Ö, Lang A, Wimo A, et al. Cost of dementia and its correlation with dependence. J Aging Health 2016;28: 1448-1464.

\section{Subspecialty Alerts by E-mail!}

Customize your online journal experience by signing up for e-mail alerts related to your subspecialty or area of interest. Access this free service by visiting Neurology.org/site/subscriptions/etoc.xhtml or click on the "E-mail Alerts" link on the home page. An extensive list of subspecialties, methods, and study design choices will be available for you to choose from-allowing you priority alerts to cutting-edge research in your field! 


\section{Neurology}

The social and economic burden of frontotemporal degeneration

James E. Galvin, David H. Howard, Sharon S. Denny, et al.

Neurology 2017;89;2049-2056 Published Online before print October 4, 2017

DOI 10.1212/WNL.0000000000004614

This information is current as of October 4, 2017

\begin{tabular}{|c|c|}
\hline $\begin{array}{l}\text { Updated Information \& } \\
\text { Services }\end{array}$ & $\begin{array}{l}\text { including high resolution figures, can be found at: } \\
\text { http://n.neurology.org/content } / 89 / 20 / 2049 \text {.full }\end{array}$ \\
\hline Supplementary Material & $\begin{array}{l}\text { Supplementary material can be found at: } \\
\text { http://n.neurology.org/content/suppl/2017/10/04/WNL.0000000000004 } \\
\text { 614.DC1 }\end{array}$ \\
\hline References & $\begin{array}{l}\text { This article cites } 34 \text { articles, } 2 \text { of which you can access for free at: } \\
\text { http://n.neurology.org/content/89/20/2049.full\#ref-list-1 }\end{array}$ \\
\hline Subspecialty Collections & $\begin{array}{l}\text { This article, along with others on similar topics, appears in the } \\
\text { following collection(s): } \\
\text { All Cognitive Disorders/Dementia } \\
\text { http://n.neurology.org/cgi/collection/all_cognitive_disorders_dementia } \\
\text { Cost effectiveness/economic } \\
\text { http://n.neurology.org/cgi/collection/cost_effectiveness_economic__ } \\
\text { Frontotemporal dementia } \\
\text { http://n.neurology.org/cgi/collection/frontotemporal_dementia } \\
\text { Quality of life } \\
\text { http://n.neurology.org/cgi/collection/quality_of_life }\end{array}$ \\
\hline Permissions \& Licensing & $\begin{array}{l}\text { Information about reproducing this article in parts (figures,tables) or in } \\
\text { its entirety can be found online at: } \\
\text { http://www.neurology.org/about/about_the_journal\#permissions }\end{array}$ \\
\hline Reprints & $\begin{array}{l}\text { Information about ordering reprints can be found online: } \\
\text { http://n.neurology.org/subscribers/advertise }\end{array}$ \\
\hline
\end{tabular}

Neurology ${ }^{\circledR}$ is the official journal of the American Academy of Neurology. Published continuously since 1951, it is now a weekly with 48 issues per year. Copyright Copyright ( 2017 The Author(s). Published by Wolters Kluwer Health, Inc. on behalf of the American Academy of Neurology.. All rights reserved. Print ISSN: 0028-3878. Online ISSN: 1526-632X.

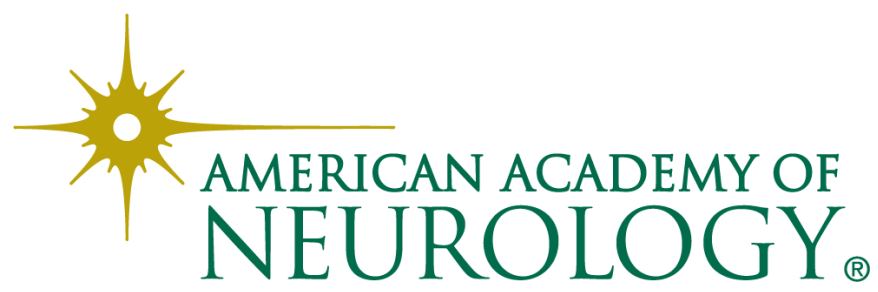

